\title{
La continuación de la guerra por otros medios. Pulares y calchaquíes en minas de plata del siglo XVII. Nevado de Acay, Salta, Argentina
}

(1) Pablo Mignone*

Fecha de recepción: 26 de noviembre de 2018. Fecha de aceptación: 29 de marzo de 2019

Palabras clave

mita minera guerras calchaquíes Nevado de Acay

\section{Resumen}

El objetivo de este trabajo es analizar la explotación minera en el Nevado de Acay (Salta, Argentina) producida entre 1655 y 1658. El estudio es de interés pues muestra el empleo de la mita minera, actividad expresamente prohibida en la época. Se analiza además la elevación del Acay a distrito minero y la de su propietario al cargo de Alcalde de Minas. El origen de los mitayos es también de interés al provenir de encomiendas de los valles de Calchaquí y Lerma. Desde uno de estos pueblos de reducción saldrá la avanzada rebelde que destruirá el ingenio minero en 1658, mostrando que la dicotomización calchaquí/pular respondió a la situación política ante el dominio español. Se plantea a futuro la interdisciplina -entre la arqueología y la historia- para comprender los procesos sociales atravesados por estos grupos, con dos hitos fundamentales como la conquista incaica y la española.

The continuation of war by other means. Pulares and Calchaquies in 17 th century silver mines. Nevado de Acay, Salta, Argentina

\section{Abstract}

Keywords

mining mita Calchaquí wars Nevado de Acay
This paper analyzes the mining activities at the Nevado de Acay (Salta, Argentina) between 1655 and 1658. The study is of interest because it shows the employment of the mining mita, activity explicitly forbidden at the time. We also analyze the elevation of the Acay to mining district and its owner to the position of Mayor of Mines. The origin of the mitayos is of interest because they came from encomiendas of the valleys of Calchaquí and Lerma. The rebellious outbreak that destroyed the mining facilities in 1658 came from one of these towns of reduction as well, showing that the Calchaquí/Pular dichotomization corresponded to the political situation created by the Spanish domination. For

* Instituto de Ciencias Sociales y Humanidades (ICSOH), Consejo Nacional de Investigaciones Científicas y Técnicas (CONICET).Salta, Argentina. E-mail: pmignone@hotmail.com 
the future, we propose an interdisciplinary approach -between archeology and history- in order to understand the social processes undergone by these groups, with two fundamental milestones such as the Inca and the Spanish conquests.

\section{Introducción}

En este escrito se presentan los avances de nuestras investigaciones sobre la ocupación humana del sector sur occidental de la puna de Salta, Argentina, en especial, en el Nevado de Acay (5.715 msnm). Aunque estas investigaciones se enmarcan en un proyecto arqueológico, las referencias históricas de un emprendimiento minero español en el siglo XVII y las medidas que tomó el gobierno colonial para explotarlo con mano de obra indígena ameritan dedicarle un estudio particular desde las fuentes históricas, quedando para otra ocasión hacer lo propio con la evidencia arqueológica.

El caso de la explotación minera en el Acay resulta de interés porque es un ejemplo particular dentro de la gobernación del Tucumán, en el cual se conocen los mineros que explotaron las vetas de plata, qué tipo de infraestructura construyeron en la montaña, la mano de obra que se empleó para estas labores, de dónde fue llevada y en qué número, las estrategias políticas desarrolladas para darle mayor entidad a un emprendimiento privado dentro de los intereses gubernamentales $y$, finalmente, su abrupto final por causa de las guerras calchaquíes.

También es importante porque suma un nuevo caso de estudio en una problemática, la minería y el trabajo indígena, donde la información es fragmentaria y más tardía (Becerra, 2014). Además, al haber sido destruido en 1658 en el marco de la tercera rebelión calchaquí nos brinda un ejemplo del alcance geográfico de dicha rebelión, de la forma en que la misma cambió el mapa étnico de la época -con la drástica disminución indígena por la muerte y las desnaturalizaciones-y de sus consecuencias ya que no se volvió a explotar el Nevado de Acay hasta bien entrado el siglo XIX.

Aunque aún está en ciernes, nuestro trabajo tiene por objetivo mostrar el análisis que venimos desarrollando sobre la explotación económica de estas minas de plata que comenzó en 1654-1655 en manos de vecinos de la ciudad de Salta que, a su vez, emplearon grupos diaguitas/calchaquíes encomendados a vecinos de esa ciudad mediante mecanismos coercitivos que no estaban amparados en la legislación vigente.

Las fuentes consultadas son principalmente actas del cabildo de Salta, provenientes del Archivo Histórico de esa ciudad, para el análisis del emprendimiento minero, cédulas de conformación de encomiendas, del Archivo General de Indias, para el estudio de las condiciones de trabajo de los grupos indígenas previas a las tareas mineras, junto a la lectura de antecedentes de investigación de especialistas sobre los distintos tipos de prestaciones laborales indígenas y las guerras contra el poder español, que dan el marco para comprender la particularidad del proceso.

Los sitios de los que hablan los documentos son hoy conocidos como "mina Milagro", ubicada a $4.700 \mathrm{msnm}$ y a $1 \mathrm{~km}$ al sur del Abra de Acay (4.900 $\mathrm{msnm}$ ), "El pueblo de la Capilla", ubicado a $4.100 \mathrm{msnm}$ sobre la ladera sur del Nevado de Acay, muy cerca de la actual Ruta nacional 40 y a escasos metros del río Negra Muerta, y "La Encrucijada”, que se encuentra 2,5 km hacia el 
sur, a la vera de la ruta 40, a $3.800 \mathrm{msnm}$ y a $500 \mathrm{~m}$ hacia el sur del origen del río Calchaquí por la unión de los ríos Negra Muerta y Barro Negro.

En esta franja de casi $5 \mathrm{~km}$ de extensión y de 3.000 hectáreas sobre la ladera sur del Acay se instaló en 1655 el ingenio minero de la Santa Vera Cruz de Acay, propiedad del capitán Gonzalo Cedano de Sotomayor, en donde funcionó también la "misión de San Bernardo de Acay", asistida espiritualmente por los padres jesuitas de San Carlos, Pedro Patricio y Hernando de Torreblanca (Torreblanca, [1696] 2007: 27-28).

A partir de esta revisión de fuentes y antecedentes surge la idea de que la minería en el Nevado de Acay está íntimamente relacionada con la aspiración del poder colonial de dar con las minas de oro y plata de las tierras de chicoanas y pulares y de explotarlas sometiendo por la fuerza a estos pueblos; anhelo que está expresado ya tanto en las cartas de Abreu (en Levillier, [1578] 1920a) y Ramírez de Velasco (en Levillier, [1588] 1920b) a los respectivos virreyes y que muestra cómo la minería argentífera en esta montaña es la culminación, en la jurisdicción de Salta, de un viejo anhelo de riqueza y de aprovechamiento de mano de obra indígena. Mano de obra que, rota la guerra en 1658, arremeterá contra los signos del poder colonial, tanto las estancias de los encomenderos, como las iglesias jesuíticas y, en especial, contra el ingenio del Acay.

\section{Los grupos diaguitas -calchaquíes y pulares- en la órbita colonial}

Para consolidar la situación de dominio sobre los amplios territorios que ocupó la gobernación del Tucumán, el poder colonial debió imponerse ante una enconada oposición indígena que se prolongó hasta el último cuarto del siglo XVII, especialmente en los valles de Calchaquí y Yocavil, en un proceso surcado por tres etapas de rebelión. La primera, desde 1534 a 1565, la segunda, desde 1630 a 1643, y la tercera, de 1656 a 1665 (Lorandi, 1988).

Con la primera de ellas, que comienza con los enfrentamientos al poder español y tiene como punto álgido el alzamiento liderado por el cacique Tolombón Juan Calchaquí (1562), empieza también la separación en el imaginario europeo de dos grupos humanos bajo los etnónimos de pulares y calchaquíes, dentro de una similar compartimentación del espacio indígena. De Atapsi -cercano al actual Seclantás, en Salta- hacia la Poma, en lo que hoy se conoce como el norte del valle Calchaquí, el llamado valle de los pulares, y desde Pompona al valle de Yocavil, el área Calchaquí (Lorandi y Boixadós, 1987-1988).

Giudicelli (2011) sostiene que no existieron diferenciaciones étnicas entre ambos pueblos y que la distinción en cuanto a las categorías va de la mano de la compartimentación espacial impuesta por los españoles: en un primer momento de la conquista, tanto el norte como el sur del valle Calchaquí ofrecen la "guazabara" como única respuesta al requerimiento español de las primeras entradas. Con el pasar del tiempo, y más particularmente a partir de la guerra de 1630 y su fin en 1643 con la desnaturalización de los rebeldes, queda como definitiva la división de regiones y una aparente distinción étnica: de Atapsi al norte, los indios domésticos sujetos al orden colonial y sus estructuras, de Atapsi al sur, los irreductibles bárbaros que, a diferencia de sus vecinos del norte, no se sujetan en orden y policía (Giudicelli, 2007: 162). 
Más política que étnica, esta distinción es en realidad fruto del proceso de pacificación mediante el cual los pulares pactaron su anexión al orden colonial luego de sufrir distintas derrotas, mientras que los pueblos del sur del valle Calchaquí -"calchaquíes" en el sentido colonial- fueron menos remisos a la sumisión al español y pudieron mantener más exitosamente su autonomía. En este sentido, el colectivo pular entra en la órbita de la dominación colonial luego de ser llevado en colleras por el gobernador Ramírez de Velasco desde el valle de los pulares hasta la boca de la Quebrada de Escoipe, en el valle de Lerma. Su fidelidad al orden español ganada por la fuerza generará desde entonces desconfianza, estableciéndose por ello la conveniencia de tenerlos alejados de su natural: "se dispuso baxarlos a lo llano de la jurisdicción y [...] nunca será conbeniente el que sean restituidos a sus tierras, por lo flaco de su fidelidad" (el Rey al virrey, 15-05-1679, en Giudicelli, 2007: 157).

Boixadós (2011) muestra otro ejemplo de la diferenciación política entre ambos sectores del valle Calchaquí. En 1634, luego de la entrada de Arias Velásquez por Escoipe y del ataque a Anguingasta para dar fin a la resistencia indígena, se produjo una asamblea de los pueblos calchaquíes en donde se dividieron las voluntades entre los que querían rendirse o negociar, asentados al norte del valle Calchaquí, y los que permanecerían en actitud de rebeldía, principalmente de los pueblos de Sicha, Gualfín, Taquigasta, Chuchagasta, Famayne, Bombolán y Tolombón.

Luego de 1643 los grupos indígenas que habitaban el sector medio del valle Calchaquí y que participaron activamente de la rebelión de 1630-1643, como los indios de Taquigasta, Sicha y Cafayate (Castro Olañeta, 2007), serán reducidos junto con los pulares en el valle de Lerma engrosando los ya existentes cuatro pueblos de pulares formados a partir de la primera encomienda, llamada de "Pulares, Escoipes y Guachipas", otorgada a uno de los miembros de la expedición fundadora de Salta en 1582, Bartolomé Valero, a las que se sumarían las distintas particiones y adiciones.

Algunos grupos más quedarán en su natural bajo el control de sus encomenderos, como los indígenas de Hualfingasta, Chuchagasta, Animaná, Bombolán, Anguingasta, Pompoma, Ampascachi, Casmichango y Tolombón, entre muchos otros. El derrotero de estas encomiendas, sus particiones y su historia desde su conformación hasta la visita de Luján de Vargas a fines del siglo XVII puede seguirse con detalle en Castro Olañeta (2007).

En el marco del surgimiento del comercio mular para abastecer el mercado altoperuano se emplearon, como estrategias de pacificación de estos colectivos indígenas, distintas prestaciones laborales que fueron mermando la población, ya sea porque los indígenas morían, huían o se quedaban en sus lugares de destino (Mata, 2005). Se empleaban alternativamente en Potosí como mineros o llevando ganado o bienes de la tierra; otros eran enviados por sus curacas a Salta para ocuparse del aprovisionamiento de la comunidad -"a comprar maíz"-; algunos más se concertaban con vecinos de Salta y Jujuy, o prestaban servicios en la estancia de su encomendero o en casas de otros vecinos. ${ }^{1}$

Estas actividades sentaron un precedente en la organización hispano-criolla de la mano de obra aborigen. A partir de 1655 los pulares y los calchaquíes -de los pueblos de Chicoana, Pulares Grande, Payogasta, Luracatao, Cachi, por citar algunos- serán trasladados desde sus respectivas encomiendas al Nevado de Acay para trabajar en las minas del capitán y Justicia Mayor de Salta, Gonzalo
1. AGl. Charcas, 101, $\mathrm{N}^{\circ} 51$ y $\mathrm{N}^{\circ} 54$. Confirmación de encomienda de pulares, 1631 y 1634 , respectivamente. 
2. AHS. Actas capitulares, Carpeta $\mathrm{N}^{\circ} 2$, f. 539r., 1649-1655.
Cedano "de la manera que [sus encomenderos] suelen sacarlos para la saca de sus ganados y otros efectos". ${ }^{2}$

\section{Las estrategias de provisión de mano de obra}

El afán de riquezas y ascenso social de la hueste española se vio magnificado por las noticias, reales o míticas, de la presencia y abundancia de oro y plata. Fue entonces la "utopía de la riqueza" (Stern, 1992: 14) lo que motivó en gran parte el esfuerzo conquistador y alrededor del cual se desarrollaron la ocupación española, la conformación de sus estructuras de poder (Assadourian, 1982; Tandeter, 1992) y la movilidad de personas y recursos a lo largo y ancho de los Andes (Bakewell, 1984).

En el actual territorio boliviano, desde que Porco primero y Potosí después se insertaron en la órbita del dominio español -a mediados del siglo XVI-, la minería fue una de las principales fuerzas motoras de la fundación de ciudades, al punto de que la minería potosina convertiría a Charcas en el centro de la economía del virreinato del Perú y en polo de atracción, tanto de la población indígena como española (Assadourian, 1982).

Esa especial gravitación de la actividad minera en lo que sería el centro jurídico del virreinato marcó otras áreas aledañas con la fundación, por ejemplo, de "ciudades efímeras" identificadas en Lípez por Gil Montero (2012), cuyo origen y duración estaban directamente vinculados a los ritmos de la producción minera.

La organización social, política y económica de la región aurífera del norte de Chile y del occidente boliviano también fue encuadrada dentro de las exigencias de la actividad (Becerra, 2014: 48). En la gobernación del Tucumán, la expectativa de riquezas de oro y plata fue una gran motivación, aunque no la única, de las primeras entradas y, en cierta forma, de las fundaciones de ciudades (Gluzman, 2007).

Con el afianzamiento del gobierno español la ocupación de recursos de potencial agrícola y ganadero en el Tucumán Colonial se fue perfilando para funcionar como abastecedor de las demandas de Potosí. Al punto de que la espacialidad de la colonia no solamente tuvo como polo de atracción esta zona del altiplano charqueño, sino que funcionó como el espejo en el cual las explotaciones auríferas y argentíferas de esta área verían su reflejo, o al menos seguirían como modelo en la esperanza de que las sucesivas fundaciones españolas igualarían en riquezas a dicho centro minero (Becerra, 2014).

Por encontrarse el Acay dentro de lo que se consideraba el límite norte del valle Calchaquí y el límite sur de los pueblos de Casabindo y Cochinoca, en la cuenca de las Salinas Grandes (Figura 1), su explotación minera surge como prolongación hacia la puna de las actividades económicas de los vecinos de la ciudad de Jujuy y sus intentos de explotar, desde fines del siglo XVI, los numerosos minerales metalíferos de los actuales departamentos jujeños de Yavi, Santa Catalina, Cochinoca y gran parte del de Rinconada. 


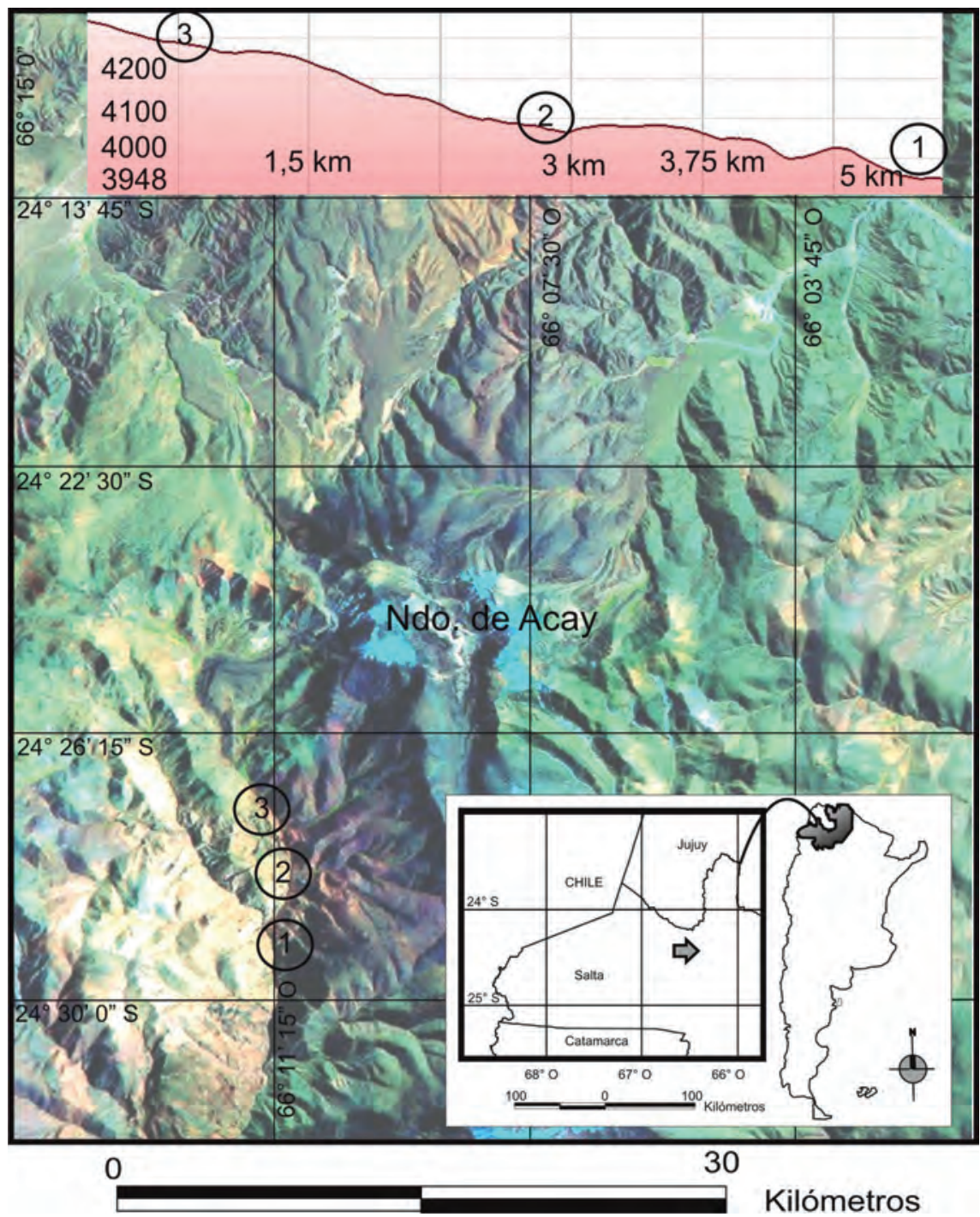

Figura 1. Ubicación de los ingenios mineros: 1. La Encrucijada, 2. "Pueblo de la Capilla" o Ingenio de la Vera Cruz, 3. Mina Milagro.

Surgen así las sociedades entre encomenderos, que por su rol en la conquista gozaban de la mano de obra indígena y de tierras en la puna, junto a mineros que carecían de ambas pero no del espíritu comercial para explotarlas en su provecho. La mina San Cristóbal de Acay, por ejemplo, fue descubierta por Pedro Rangel, minero asociado hacia el primer cuarto del siglo XVII a los conquistadores Juan Pablo Guzmán, Felipe y Antonio de Hermella en la explotación de minas en Cochinoca y la Rinconada (Becerra, 2014: 234).

Desconocemos las razones por las cuales en menos de veinte años ya no son vecinos de Jujuy sino de Salta los que están involucrados en la explotación de las minas de Acay. Quizás un motivo importante fue tanto la continuidad de los litigios entre los vecinos hacia el siglo XIX (estudiados por Albeck y Palomeque, 2009) como la limitada cantidad de mano de obra indígena disponible en la puna jujeña que marca el padrón de indios de 1654 en ocasión del otorgamiento de la encomienda de Casabindo y Cochinoca a Pablo Bernárdez de Ovando (1654), en donde se observa que la mitad de los tributarios están 
ausentes y asentados en el Valle Rico, Moraya, Moxo, Tarija, Suipacha, Tojo y el asiento de Lípez (Palomeque, 2006).

En cambio, luego de la pacificación del "Gran Alzamiento" calchaquí (16301643) quedó a disposición de los españoles avecindados en la ciudad de Salta un número importante de indígenas reducidos en encomienda en el sector norte del valle Calchaquí y el sector noroccidental del valle de Lerma, ubicados a 50 y $100 \mathrm{~km}$ del Nevado de Acay, respectivamente.

A este incentivo puede sumársele el cambio en la orientación de la actividad económica de los vecinos del Tucumán, que pasaron de estar interesados en hacer entradas y descubrimientos que les permitiesen mantenerse alejados e independientes del poder central (Palomeque, 2006: 19) a preocuparse, una vez sofocadas las dos primeras rebeliones calchaquíes, por expandir hacia Charcas las redes comerciales y mantenerlas seguras.

Si se medita sobre la significación de la frase toledana, de que sin las riquezas mineras del Potosí el Perú no vale un Tucumán, se podrá entender la necesidad perentoria en la que se encontraba la gobernación para justificar su existencia y la esperanza en el rol de la minería en este marco comercial.

Al igual que en otras actividades económicas, existía la necesidad de una provisión constante de mano de obra lo que llevó a la extensión de la obligación de la mita de plaza hacia la minería, movilizando a miles de mitayos hacia distintos centros mineros andinos (Becerra et al., 2016).

El virrey Toledo institucionalizó la mita minera durante el siglo XVI para organizar el trabajo en las minas del altiplano mediante las Ordenanzas de las minas de Plata de Potosí y Porco (1574). Para la gobernación del Tucumán surgieron otras normativas por iniciativa de los gobernadores para el mismo efecto, como las de Ramírez de Velasco quien quiso replicar el sistema potosino en Famatina haciendo que cada encomienda destinara una sexta parte de sus mitayos no solo para activar la producción de metálico sino también para que la mano de obra indígena accediera a la moneda a fin de cumplir con el tributo (Becerra et al., 2016).

Como sostiene Sica (2014) la mita fue uno de los sostenes del orden colonial en América, basado en un trabajo compulsivo orientado hacia las tareas que permitían consolidar el poder español, como la minería, la agricultura, la ganadería, la construcción y otras actividades conexas. La mita de plaza consistía en el aporte de mano de obra indígena por el que los vecinos que no poseían encomiendas podían acceder a la misma, la que a su vez era empleada principalmente para el trabajo en las ciudades, en el servicio y construcciones de las casas y de su infraestructura, en las tareas agrícolas y ganaderas y en los oficios manuales, excluyéndose a partir de 1612 por las Ordenanzas de Alfaro las labores mineras (Sica, 2014).

Aunque las ordenanzas del oidor Alfaro prohibieron la prestación de la mita, en especial en la penosa labor de los socavones, podían no obstante concertarse libremente en ellas de forma tal que no se desviaran trabajadores de la mita de plaza hacia las minas y que pudiesen negociar con un poco más de holgura las condiciones de su prestación laboral, llegando incluso a recibir una remuneración mayor que la de los mitayos (Sica, 2014). 
Estas ordenanzas no fueron bien recibidas por los vecinos del Tucumán, lo que dio lugar a diversas prácticas de utilización de la fuerza de trabajo, muchas de ellas reñidas con el marco legal vigente, desde el concierto voluntario, el desvío de la mita de plaza a las minas y las prácticas ilegales de traslado (Becerra et al., 2016), que contemplaban la mancomunidad entre los intereses de la corona - para el aumento de sus reales quintos o para descarga de la real conciencia, como justificaciones más repetidas- y la de algunos vecinos que ostentaban a la par cargos gubernamentales o se encontraban muy cercanos a ellos por relaciones familiares o de amistad.

A partir de la tercera fundación de Jujuy en 1593 sus pobladores beneficiados con encomiendas de indios aplicaron los tipos de aprovechamiento de mano de obra antes mencionados, en particular la mita minera alegando ante quienes se veían perjudicados por la merma de la mita de plaza que los reales quintos así lo justificaban. Ante los pedidos de los vecinos a las autoridades coloniales para gozar de este beneficio en sus minas de la puna, la Audiencia de Charcas autorizó el empleo de mitayos en abierta contradicción con las ordenanzas de Alfaro (Becerra et al., 2016).

Un caso similar se observa en el sur del valle Calchaquí, en la Sierra del Aconquija, en donde hacia fines del siglo XVII fueron descubiertas importantes vetas de mineral (Rodríguez, 2015). En ambos casos se crearon, bajo el amparo de las ordenanzas del virrey Toledo (1574), jurisdicciones mineras encabezadas por una autoridad administrativa y judicial en lo civil y lo criminal -el alcalde de minas en el caso de Jujuy, teniente para el caso del Aconquija- cuya competencia se circunscribía a todos los asuntos relacionados con las actividades mineras, al modo en que se habían erigido en el área central del virreinato del Perú y, en particular, en Potosí (Rodríguez, 2015).

El traslado de mitayos que servían en las ciudades de Tucumán y Catamarca a las minas de Retamoso, su descubridor, muestra el contraste entre la obediencia a la normativa, con respecto al establecimiento de jurisdicciones mineras, y el olvido deliberado de la legislación atinente a la prestación laboral indígena que prohibía esta práctica expresamente.

En el caso que nos ocupa se da una situación similar pero aún más acendrada a guisa de lo que ocurría en Potosí, en cuanto a que se crea para el caso del Acay una jurisdicción minera con su alcalde de minas, figura que no aparece en la explotación del Aconquija, lo cual demuestra, como se verá a continuación, la importancia dada a este nuevo asiento minero por parte del gobernador Mercado y Villacorta.

\section{La mita minera al Nevado de Acay}

Si bien aún no está claro el marco en el cual se produce la sustitución de la mita de plaza por la mita minera en el caso analizado, la situación a la que remiten algunas sesiones del cabildo de Salta hacia mediados del siglo XVII nos indican que fue legitimada por dos aspectos. Por un lado, la esperanza siempre presente de riquezas minerales en la jurisdicción de Salta, y, por otro, la necesidad de someter a través del trabajo a los grupos indígenas que, a pesar de pasado ya el segundo alzamiento y de que los grupos del norte del valle habían sido pacificados, seguían generando intranquilidad en la ciudad y sus alrededores. 
3. AHS, Actas capitulares, Carpeta $\mathrm{N}^{\circ} 2,1649-1655$.
4. En numerosas ocasiones se observa lo gravoso que significaba para los indígenas el trabajo forzado en las minas. Con motivo del hallazgo de minas realizado por Juan Ortiz de Urbina, vecino de Salta, en las cercanías del actual pueblo de Seclantás, en 1630 sus encomendados, calchaquíes y pulares, se rebelaron matándolo -junto a otros españoles e indios de servicio- y tomando como rehenes a "cuatro doncellas españolas" (Giudicelli, 2018). Otro ejemplo de resistencia lo vemos luego de la pacificación del valle calchaquí en 1665 , en el pedido al gobernador del cacique de Anguinao, Pedro Aochoca, para que le diera tierras fuera del valle a fin de no tener que sufrir el trabajo en las minas: “...porque cuando hemos ido á Potosí, hemos visto á los Indios, que entran á la labor del cerro á sacar plata, y entran el lunes debajo de tierra, y salen el sabado" (Torreblanca, 2007: 108).

5. AHS, Actas capitulares, Carpeta № 2, f. 364r., 1649-1655.

6. AHS, Actas capitulares, Carpeta № 2, f. 362r., 1649-1655.

7. AHS, Actas capitulares, Carpeta № 6, f. 539r., 1655 .

8. El término ingenio indica que se desarrollaron allí todas las labores del proceso minero, desde el picado para la obtención del mineral en bruto, la molienda, el refinamiento, la fundición y el beneficio por medio del azogue, además de su transporte y acarreo a Potosí para ensayar y verificar su ley.

9. AHS, Actas capitulares, Carpeta № 6, f. 541v., 1655 .
En sesión del cabildo del 30 de agosto de $1649^{3}$ se indicaba que no debía dejarse desguarnecida la ciudad con su gente de guerra por el peligro de que los pulares, a pesar de ser aliados, encabezasen un asalto llevando consigo a los calchaquíes a la rebelión. Generaba desconfianza el haberse negado a dos hechos de importancia: en primer lugar, a acudir al llamado del gobernador para hacer entrada contra los indios tobas y mocovíes que asaltaron el pueblo de Ocloyas y, en segundo lugar, a revelar la ubicación de las riquezas mineras en sus territorios, concitando a su vez a los diaguitas del valle Calchaquí y del valle de Hualfín a la resistencia. ${ }^{4}$

La razón de más peso que dan al cabildo los padres de la Compañía de Jesús, entre ellos el padre Torreblanca, es la desconfianza que generaban por su ambivalencia en las rebeliones calchaquíes. Su fidelidad oscilaba según evaluaban el destino de la guerra contra los españoles, "aguardando una ocasión para ejecutar su maldad como en años pasados lo hicieron debajo de amistad". ${ }^{5}$

En ese momento no es la guerra sino el trabajo en las minas, precisamente, el medio elegido para doblegar la resistencia del colectivo pular-calchaquí. Contrariando a las ordenanzas de Alfaro pero viéndose en la necesidad de reactivar una economía descalabrada, y una igualmente soliviantada obediencia indígena tras largos años de guerra (Lorandi, 2005), las autoridades españolas dispondrán que los indígenas podrán ser repartidos dentro de turnos de mita debiéndoseles pagar seis reales por día todos los lunes de las semanas -con multa de ocho reales por no acudir a la mita-, manteniendo sin embargo la prohibición de reducirlos al servicio forzado bajo penas de 500 pesos y cárcel. ${ }^{6}$

Quizás es por esta necesidad de pacificación de la frontera calchaquí que la mita minera resulta anterior al hallazgo de una veta que la justifique, a diferencia del caso del Aconquija en el valle Calchaquí sur analizado por Rodríguez (2015), en el que ocurre todo lo contrario. En el caso de Salta, el desvío de los indígenas de su labor en la ciudad hacia las minas del Acay se da incluso sin la intervención del gobernador, la cual se produce en 1655, un año después de que ocho trabajadores calchaquíes fuesen llevados a la montaña por los descubridores de las minas de plata.

Aunque no contamos aún con información de las labores desarrolladas por Pedro Rangel luego del descubrimiento de minas en Acay, en marzo de 1655 se dan a conocer referencias detalladas del comienzo de la explotación de sus vetas argentíferas. Por la magnitud del emprendimiento y por las noticias de minas cercanas, el gobernador Mercado y Villacorta decide desviar de la mita de plaza un contingente de indígenas de los valles de Lerma y Calchaquí, reducidos en encomienda, ${ }^{7}$ para la construcción de los ingenios mineros ${ }^{8}$ en el asiento de la Vera Cruz de Acay, propiedad de Gonzalo Cedano Sotomayor y Joseph Passe, situado a treinta leguas de la ciudad de Salta (Figura 2).

Como se observa en la Tabla 1, cada encomendero o administrador debía aportar a la mita en el mes requerido veinticinco indígenas en caso de los calchaquíes, o uno sólo en el caso de los pulares, en turnos rotativos de cinco meses, que se sumarían a los ocho calchaquíes ya asignados por el cabildo antes de mayo de 1655, y hasta "que se acabe de hacer y edificar el Ingenio de agua de moler metales que están haciendo en el dicho Ingenio". ${ }^{9}$ 

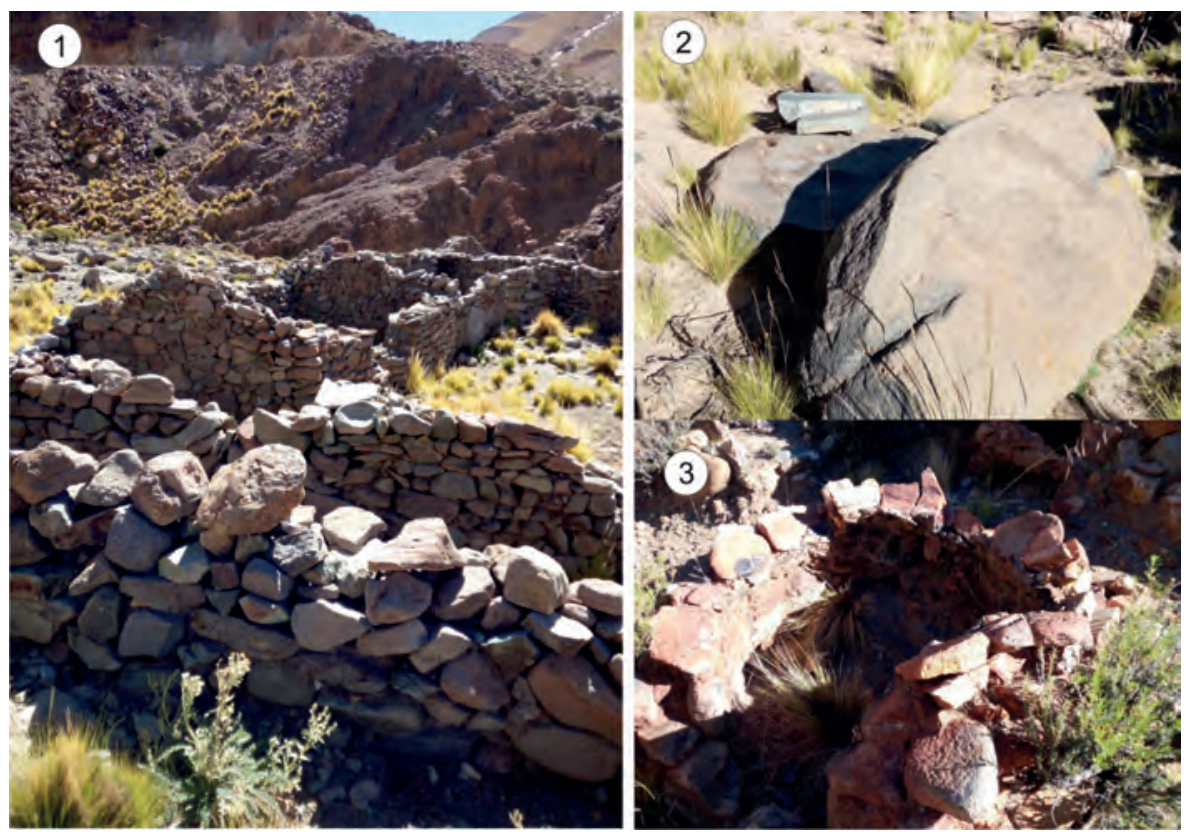

Figura 2. Fotografías del "Pueblo de la Capilla": 1. Vista general; La Encrucijada: 2. piedra de moler y 3. horno de fundición.

\begin{tabular}{|c|c|c|c|c|}
\hline \multirow{2}{*}{ Encomendero/administrador } & \multirow{2}{*}{ Encomienda } & \multicolumn{2}{|c|}{ Origen } & \multirow{2}{*}{ Total } \\
\hline & & Pulares & Calchaquíes & \\
\hline Francisco Arias Velásquez (administrador) & Hualfingasta & & $x$ & 25 \\
\hline Pedro de Aguirre (encomendero) & Anquingasta & & $x$ & 25 \\
\hline Juan López de Córdoba (administrador) & Chuchagasta y Tolombón & & $x$ & 25 \\
\hline Francisco de Lisondo (administrador) & Taquigasta & & $\mathrm{x}$ & 25 \\
\hline $\begin{array}{l}\text { Juan de Abreu } \\
\text { (encomendero) }\end{array}$ & $\begin{array}{l}\text { Animaná, Bombolán, } \\
\text { Polinda y Vilti }\end{array}$ & & $x$ & 25 \\
\hline Diego Ruiz de Alarcón (administrador) & Ampascachi & & $x$ & 25 \\
\hline Juan Rodríguez Salazar (encomendero) & Tolombón & & $\mathrm{X}$ & 25 \\
\hline Sancho Pérez Morillo (encomendero) & Casmichango & & $x$ & 25 \\
\hline Luis Arias Velásquez (encomendero) & Payogasta & $x$ & & 1 \\
\hline José Vélez de Alcocer (encomendero) & $\begin{array}{c}\text { Pulares } \\
\text { (valle Calchaquí) }\end{array}$ & $\mathrm{x}$ & & 1 \\
\hline Pedro de Lara Manjarrés (encomendero) & $\begin{array}{c}\text { Pulares } \\
\text { (valle de Lerma) }\end{array}$ & $x$ & & 1 \\
\hline Alonso del Castillo (administrador) & Luracatao & $x$ & & 1 \\
\hline $\begin{array}{l}\text { Diego de Trejo } \\
\text { (encomendero) }\end{array}$ & $\begin{array}{c}\text { Pulares } \\
\text { (valle de Lerma) }\end{array}$ & $\mathrm{x}$ & & 1 \\
\hline Andrés de Frías Sandoval (encomendero) & $\begin{array}{c}\text { Pulares } \\
\text { (valle de Lerma) }\end{array}$ & $\mathrm{x}$ & & 1 \\
\hline Miguel de Elizondo (encomendero) & Escoipe, Pulares y Guachipas & $x$ & & 1 \\
\hline Margarita Chávez (encomendera) & Cachi & $x$ & & 1 \\
\hline Juan Castellanos (encomendero) & Chicoana & $x$ & & 1 \\
\hline Tomás Castellanos de Escobar (encomendero) & Chicoana & $x$ & & 1 \\
\hline
\end{tabular}

Tabla 1. Vecinos feudatarios e indígenas aportados por mes. Fuentes: AHS. Actas Capitulares, Carpeta № 6, año 1655: f. 541v. y Castro Olañeta (2007: 13). 
10. AHS, Actas capitulares, Carpeta № 6, f. $545 \mathrm{~V}$., 1655 .
11. AHS, Actas capitulares, Carpeta № 6, f. 541r., 1655 .

12. AHS, Actas capitulares, Carpeta № 6, f. $558 \mathrm{v}, 1655$.
La diferencia entre ambos grupos se tradujo también en la paga por los trabajos en las minas, a los calchaquíes les correspondía un real cada día y a los pulares un real y medio por ser indios amigos, montos a ser pagados en mano y no en especie, a lo cual debía sumarse su manutención. ${ }^{10}$

Debido a que en el mismo cerro se concentraban varios emprendimientos la cantidad de indígenas se repartió según su magnitud. De esta manera, el capitán Gonzalo Cedano de Sotomayor y su socio, el capitán don Joseph Passe, serían los "primeros y más privilegiados" y recibirían cada mes treinta indios.

Los restantes veintidós serían repartidos entre Juan Masiel, quien estaba haciendo otro ingenio y tenía construida una acequia y un trapiche para moler a mano metales, y entre los socios Domingo Fernández Cabezas y Francisco de los Ríos, por un lado, y don Diego de Armenta, por el otro, quien además de estar labrando minas como los anteriores necesitaba la confección de hornos para fundir los metales soroches que había sacado de dicho asiento.

Esto debía hacerse siempre y cuando las minas diesen fruto de provecho en planchas de plata, por lo que cada mes un capitular del cabildo sería enviado a evaluar su cantidad y ley. En caso de no reconocerse fruto, el gobernador establecería quitarles los indios y dárselos a Masiel para que con más brevedad acabe de edificar su ingenio. ${ }^{11}$

Un emprendimiento de cierta magnitud, que ameritaba una población constante de 68 personas, no tardó en ser elevado a distrito minero. Dos meses después de la convocatoria el gobernador hizo conocer a los vecinos de Salta el nuevo cargo del dueño del asiento minero de la "Vera Cruz", Gonzalo Cedano, de "alcalde mayor de minas como en la Villa Imperial de Potossi" con jurisdicción no solo en el cerro de Acay sino también en todos los minerales y asientos del distrito y de la jurisdicción de la ciudad de Salta, con poder en las causas civiles y criminales, como también en el otorgamiento de pedimentos de futuras explotaciones mineras. ${ }^{12}$

La relativa paz del primer cuarto del siglo XVII y la pretendida prosperidad del emprendimiento económico será rota con la tercera rebelión calchaquí (1656 a 1666) encabezada por el andaluz Pedro Chamijo o Bohórquez y secundada por algunos grupos del valle de Yocavil -calchaquíes, principalmente sichas y cafayates- y pulares -cachis, chicoanas y payogastas- (Lorandi, 2005).

Junto a las distintas fundaciones españolas y misiones jesuíticas embestidas por los rebeldes, en 1658 se produjo el ataque al ingenio del Acay desde el cercano pueblo de Payogasta (70 km al sur del ingenio), produciéndose su destrucción y abandono (Torreblanca, 2007). Su derrota y desnaturalización en la boca de la Quebrada de Escoipe en 1662 abrirá una nueva etapa de la configuración colonial en el sector centro-occidental del valle de Lerma, y también traerá consecuencias al pretencioso distrito minero destruido por su rebelión.

Un año después de la completa pacificación de la frontera calchaquí y de las desnaturalizaciones masivas de los indígenas rebelados, los alcaldes de minas de Nuestra Señora de Talavera de Madrid de Esteco (1609-1692) otorgaron la explotación de las vetas de Acay a un vecino de la ciudad, Pedro Flores (Tolosa, 2015), lo cual indica, por un lado, que la iniciativa minera se había desplazado hacia el sur de la jurisdicción de Salta habiendo desaparecido de la escena el distrito de Acay y su alcalde de minas. Por el otro, que en 1665 los centros desde los cuales se habían realizado los ataques al ingenio recién creado ya no 
presentaban peligro como fruto de la política de desnaturalización, mientras comenzaba a perfilarse la frontera oriental contra el indígena chaqueño.

A esta situación se le suma la falta de mano de obra calificada disponible en la gobernación, lo cual forzaba a buscar indígenas mineros en Potosí debido a los esfuerzos, más o menos exitosos desde la implementación de las ordenanzas de Alfaro en 1612 por erradicar la figura del servicio personal y del traslado de las poblaciones indígenas fuera de su jurisdicción (González Rodríguez, 1984).

En 1671 el gobernador Angelo de Peredo reconoció en los pueblos y reducciones indígenas de Salta una notoria disminución que respondía a la continuidad de la práctica de los encomenderos de enviar a los indígenas a haciendas o chacras, tanto de su propiedad como de otros vecinos, o para el arreo de mulas y vacas tanto dentro como fuera de las jurisdicciones respectivas (González Rodríguez, 1984: 54).

Para levantar una información completa de esta situación irregular, el gobernador envió al corregidor de las reducciones de Salta, Francisco de Páez, junto al Justicia Mayor de este distrito, Antonio de Cabrera, a todas las encomiendas para indagar acerca del incumplimiento de las leyes en las que estaba enmarcada la prestación laboral indígena.

El informe de Antonio de Cabrera revelaría que, casi veinte años después, la relación de 62 a 1 de los calchaquíes y pulares afectados a la minería de Acay estaba ecuánimemente distribuida, esta vez, en detrimento de los pulares. De las dieciocho encomiendas de la jurisdicción de Salta registradas por Cabrera, las encomiendas de pulares -encomienda de Payogasta de Luis Arias Velásquez, y Pulares Grande de Diego Vélez de Alcocer, por ejemplo-, son las que presentan un mayor porcentaje de trasladados, llegando a casi un $80 \%$ de población tributaria (González Rodríguez, 1984: 54).

Una vez pacificada la frontera calchaquí y a pesar de que los grupos pulares siguieron manteniendo sus tierras en el valle de Lerma y los indígenas del valle Calchaquí fueron desnaturalizados, el servicio personal desdibujó la relación amigo/enemigo que distinguía a los calchaquíes de los pulares antes del tercer alzamiento.

Las necesidades económicas y la petición constante de los vecinos del Tucumán de que se tenía urgencia de gozar del servicio personal en ausencia de otros recursos, para sacar "los frutos de la tierra e ganados a las prouinçias del/ Pirú e particularmente a la villa de Potossí/ y ciudad de La Plata" (Charcas, 34, folios 49v.-55. Año 1613, en Pérez Sáez y Ossán de Pérez Sáez, 1997: 96), parece haber eliminado la ventaja que poseían los pulares con respecto a sus belicosos vecinos.

Las tierras de reducción en donde fueron dispuestos por el gobernador Mercado y Villacorta, de una legua cuadrada en atención a la normativa vigente, cuyo valor fue fijado en 1.200 pesos, fue pagada por estos indígenas también en la forma del servicio personal, lo cual significó, por un lado, tener cierta fuerza para defender estas tierras en sucesivos litigios ante españoles que les disputaban la propiedad y, por el otro, el despoblamiento del valle (Mata, 2005).

A fines del siglo XVII el cura propietario de la doctrina de Chicoana informó que los indígenas de los pueblos que fueron puestos por el gobernador 
13. Nicolás Severo de Isasmendi, último gobernador de la Intendencia de Salta del Tucumán (1809-1810), fue propietario de la hacienda de Molinos $y$, entre otras cosas, de una enorme franja de terreno que, de sur a norte, terminaba en "una loma que desciende del cerro alto llamado aCay pasada de la Sienaga redonda Ilamada Caracha-Pampa, lindero de la Señora Marquesa de Toxo" (Expediente de solicitud del título de Conde de la Trinidad de Nolasco, en Cornejo, 1945: 429).

14. AHS, Caja № $12 \mathrm{~A}, 1789$.

15. Hacia 1802, y por el artículo 134 de la Real Orden de Intendentes, se permitió realizar el rescate de los metales a los mineros cuyas labores quedasen en la jurisdicción de Salta. Sin embargo, la Real Tesorería de Salta no podía hacerse cargo del rescate por no haber dinero excedente ni “azogues en esta Tesorería ni quizás en los Reales Almacenes de Buenos Aires" (Becerra, 2014: 219).
Mercado y Villacorta en su doctrina estaban "disipados y fuera de sus reducciones los indios con sus mugeres e hijos en las estancias y chacras de sus encomenderos, sujetos a servicio personal" (Carta del Obispo de Tucumán, en Mata, 2005: 61).

Uno de estos grupos reducidos en el valle de Lerma que hemos visto llevados a la mita minera, los payogastas, luego de habérseles asignado sus tierras de comunidad y pagado por ellas fueron trasladados a mediados del siglo XVIII a la hacienda de Molinos de su encomendero, Domingo de Isasmendi, en el valle Calchaquí central. Las propiedades de este encomendero incluyeron el Nevado de Acay, al cual su hijo, Nicolás Severo de Isasmendi, ${ }^{13}$ ofrecerá como parte de pago en su intento por adquirir el título de Conde de la Trinidad de Nolasco.

Algunas referencias indirectas sugieren que a finales del siglo XVIII Isasmendi buscó explotar las minas de plata para lo cual solicitó al gobernador de la Intendencia de Salta, Andrés Mestre, el permiso respectivo y el azogue para el beneficio de las menas; ${ }^{14}$ un bien que ya era escaso entonces y difícil de conseguir.

La tarea no parece haber prosperado, en parte por ser general en los emprendimientos mineros de la zona la falta de indígenas y las dificultades propias de las disposiciones coloniales con respecto al rescate de las piñas extraídas de las menas, que debían ser enviadas a Potosí para proceder a la fundición y ensaye y el cobro de los reales quintos, proceso muy demandante en términos de tiempo y recursos. ${ }^{15}$

Por ejemplo, José González Tames descubridor y propietario de la mina San Francisco de Asís, en San Antonio de los Cobres, refirió a la Intendencia de Salta que a las dificultades para el progreso de la minería mencionadas en los párrafos anteriores, se le sumaba la poca disponibilidad de mano de obra indígena. Ésta, a fines del siglo XVIII y principios del XIX, se caracterizaba en muchos casos por estar fuera de la estructura tributaria de la mita y ser de carácter independiente, con trabajadores diestros en los procesos mineros y, muchas veces, disputando la propiedad y la explotación a los españoles mismos.

Como señala Tames, el problema radicaba en que los mineros en actividad eran casi todos indígenas que, al no estar dentro de una estructura que los forzara a seguir produciendo, una vez que encontraban lo que les bastaba dejaban de trabajar. Es por ello que solicitó a la Intendencia que le proveyera de una mita de indígenas encomendados para tener una provisión constante de trabajadores, lo cual le fue concedido. Se resolvió entonces destinar de la encomienda de Isasmendi, Molinos, y de Cochinoca y Casabindo, de La Rinconada, Los Cerrillos y Santa Catalina, en las proximidades del mineral, una mita de indígenas con una duración de cuatro meses (Becerra, 2014: 263).

El pueblo de Payogasta, descendiente de aquella reducción cuyos miembros trabajaron el mineral de Acay, será empleado esta vez a $50 \mathrm{~km}$ al norte de esta montaña, participando de las tareas mineras alternadamente para que se acostumbren "todos al trabajo con beneficio público y de ellos mismos" (Becerra, 2014: 263-264), en un contexto sensiblemente distinto al reinante a mediados del siglo XVII, por las Reformas Borbónicas y sus medidas tendientes, entre otras cosas, a aumentar la renta obtenida de las colonias americanas.

En este marco, con el fin de afianzar la hegemonía peninsular en los territorios de ultramar, se desarrolló una contradicción entre el fomento de la prestación 
laboral voluntaria y su obligatoriedad, debido a que las leyes condenaban la "vagancia y ociosidad" (Rodríguez, 2015; Becerra et al., 2016). Al enfrentarse con el problema constante de conseguir mano de obra para las labores mineras, la mita será conformada por "los indios sanos, robustos y menos ocupados", así como por "los blancos, mestizos, y zambos vagos, ociosos o mal entretenidos que se contemplen necesarios" (Becerra, 2014: 264).

Estos trabajadores serán destinados a las minas de José González Tames "de reciente laboreo", mientras que el ingenio de la Vera Cruz en la Cordillera de Acay, según se hace constar en un documento de la Real Hacienda de Buenos Aires de 1802, se encontraba abandonado. ${ }^{16}$

Las siguientes noticias de las explotaciones mineras en el Acay se retoman una vez desarticulado el virreinato del río de la Plata, tras la llegada a sus antiguos territorios de naturalistas extranjeros para "modernizarlas" y situarlas dentro del creciente capitalismo industrial (Rodríguez, 2015). Luego del paso de viajeros y naturalistas por las minas -como Abraham Becerra, Otto Klix, Hóskold y Reichert (Mignone, 2014)- enviados por el gobierno local para posicionar a la puna en el negocio de la explotación de boratos, las vetas de plata pasaron a formar parte de una propiedad llamada "Quebrada de las Minas" y "Dentro Minas"17 de 3.076 hectáreas. Esta fue vendida en 1924 en remate público a José Maíz Pérez, español, quien intentó nuevamente la reactivación del ingenio hasta su muerte en 1940. Los detalles de este moderno emprendimiento escapan a los objetivos de este trabajo.

\section{Palabras finales}

El escrito presentado muestra que existió una lógica de continuidad y alternancia entre la guerra y el trabajo forzado como forma de pacificación de la frontera calchaquí. Se desprende a su vez de este análisis que la explotación de la mano de obra indígena en la minería "de la manera que [sus encomenderos] suelen sacarlos para la saca de sus ganados y otros efectos", ${ }^{18}$ fue vista como una especie particular de servicio personal, menos librada "a la iniciativa y a las posibilidades del encomendero" (Doucet, 1986: 65-66), como era el servicio personal hasta entonces, aunque igualmente forzada por el viejo anhelo de las riquezas de oro y plata cercanas a los chicoanas y los pulares que los gobernadores del Tucumán, Gonzalo de Abreu y Figueroa y Juan Ramírez de Velasco, se habían propuesto obtener por la fuerza de las armas -el primero en 1578 y el segundo en 1588.

Vimos también que la importancia atribuida a las minas del Acay dentro de este anhelo de riquezas queda manifestada no solamente en la falta de acatamiento de las ordenanzas de Alfaro de 1612, que prohibían expresamente la mita minera -lo cual era algo normal- sino principalmente en el hecho de que el ingenio del Acay se conformó en distrito minero y su descubridor, Gonzalo Cedano, en alcalde de minas con poder en lo civil y lo criminal, en ese rubro económico, en toda la jurisdicción de Salta.

Otro aspecto a destacar es que el caso analizado muestra cómo las categorías con las cuales los españoles segregaron la diversidad étnica del valle Calchaquí en la oposición "indios amigos" (pulares) y "belicosos" (calchaquíes) es un producto coyuntural y político, ya que el contexto del comienzo de esta explotación minera se produce en los momentos previos al tercer alzamiento calchaquí, en un marco de inestabilidad política en el cual no se había disipado
16. AGN. Tribunales 36-2-5, f. 9v., 1802 .

17. Dirección General de Inmuebles de la Provincia de Salta, Matrículas 50 y 51 , respectivamente.
18. AHS, Actas capitulares, carpeta $\mathrm{N}^{\circ} 2$, f. 539r., 1649-1655. 
aún la amenaza de una rebelión, incluso de los "indios amigos" de la frontera occidental de Salta, cuya forzada inserción en el sistema colonial dejaba latente la posibilidad de nuevos intentos por lograr su libertad.

En este sentido resulta paradójico que los "indios amigos", que habían realizado su prestación laboral en el Acay durante tres años en situación más ventajosa que los calchaquíes, se organizaran desde el pueblo de Payogasta y destruyeran el ingenio del Acay poniendo en retirada al flamante alcalde de minas, y dando por el suelo con las ansias de "aumentar los reales quintos" en "provecho de toda la gobernación".

La desnaturalización de los indígenas aliados a Bohórquez a partir de 1662 en la boca de la Quebrada de Escoipe, en el valle de Lerma, abre una nueva etapa para la historia de estos "indios amigos", quienes reducidos junto a los calchaquíes comenzarán un nuevo periplo contra el gobierno hispano-criollo para defender sus tierras de reducción ante los intentos de apropiación de los vecinos, encomenderos y órdenes religiosas en el marco de una revalorización de la propiedad agraria en el valle de Lerma (Mata, 2005).

Las investigaciones que venimos desarrollando en arqueología histórica continuarán con la combinación, en un mismo cuerpo discursivo, de las materialidades que surgen del trabajo de campo y de la búsqueda y análisis de fuentes históricas para poder reconstruir el derrotero de los grupos indígenas dentro del orden colonial, tanto en el Nevado de Acay como en sus tierras de reducción de la quebrada de Escoipe, identificando también rupturas y continuidades entre ambos espacios desde los momentos previos a la conquista incaica. De esta manera, esperamos tener un panorama más acabado de la historia prehispánica y colonial de los grupos diaguitas/calchaquíes a escala regional, para obtener una visión diacrónica de la profundidad de los cambios sufridos por estos colectivos indígenas durante las dos colonizaciones sucesivas.

\section{Agradecimientos}

Al CONICET, a mis directoras María Ester Albeck y Sara Mata, a los dos evaluadores anónimos por sus valiosas sugerencias, a la directora del Museo de Antropología de Salta, Mirta Santoni, a Fernanda López por la lectura del manuscrito y su colaboración en mejorarlo, a Cecilia Castellanos y Andrea Villagrán por el aporte de bibliografía y a la familia Borelli por los permisos otorgados para realizar los sucesivos trabajos de campo. 


\section{Q Abreviaturas}

"Archivo General de Indias (AGI)

»Archivo General de la Nación (AGN)

» Archivo Histórico de Salta (AHS)

\section{Q Fuentes documentales citadas}

»AGl. Charcas, 101, N 51, Confirmación de encomienda de pulares, etc.

»AGl. Charcas, 101, N 54, Confirmación de encomienda de pulares, etc.

»AGN. Tribunales 36-2-5, Año 1802, sobre el mineral de San Francisco.

»AHS. Actas capitulares, Carpeta $N^{\circ} 2,1649-1655$.

» AHS. Actas capitulares, Carpeta N6, año 1655.

»AHS, Caja 12A, Año 1789, Solicitud de N. Severo de Isasmendi de 400 libras de azogue.

»Dirección General de Inmuebles de la Provincia de Salta, Matrículas 50 y 51. 


\section{Q Bibliografía citada}

"Albeck, M. E y S. Palomeque (2009). Ocupación española de las tierras indígenas de la puna y "raya del Tucumán" durante el temprano período colonial. Memoria Americana. Cuadernos de Etnohistoria 17 (2): 173-212.

"Assadourian, C. (1982). El sistema de la economía colonial. Mercado interno, regiones y espacio económico. Lima, Instituto de Estudios Peruanos.

" Bakewell, P. (1984). "Mining in colonial Spanish America" en Bethell, L. (ed.), The Cambridge History of Latin America. Vol. 2: 105-151. Cambridge, CambridgeUniversityPress.

" Becerra, F. (2014). “'Para labrar y poblar'... Prácticas minero-metalúrgicas en la Puna de Jujuy durante el período colonial (siglos XVII-XVIII)". Tesis para optar por el título de Doctor, especialidad Arqueología. Buenos Aires, Facultad de Filosofía y Letras de la Universidad de Buenos Aires. Disponible en: http://repositorio.filo.uba.ar/handle/ filodigital/4330. Consultado el: 26 de mayo de 2018.

» Becerra, F.; Estruch, D.; Rodríguez, L. y M. V. Staricco (2016). “'Esperanzados de resarcir los quebrantos y de aumentar sus intereses': emprendimientos mineros coloniales en el Antiguo Tucumán en Uribe Salas, J. A.; Herrera Canales, I; Parra Campos, A.; Escamilla González, F. O. y L. Morelos Rodríguez (comps.), Economía, sociedad y cultura en la historia de la minería latinoamericana: 111-124. México DF, Facultad de Historia de la Universidad Michoacana San Nicolás de Hidalgo/Dirección de Estudios Históricos del Instituto Nacional de Antropología e Historia y la Facultad de Ingeniería de la Universidad Nacional Autónoma de México.

» Boixadós, R. (2011). "Rebeldes, soldados y cautivos. Etnohistoria de un episodio en la frontera de guerra del Valle Calchaquí (1634)" en Rodríguez, L. (ed.), Resistencias, conflictos y negociaciones. El Valle Calchaquí desde el periodo prehispánico hasta la actualidad: 93-121. Rosario, Prohistoria.

»Castro Olañeta, I. (2007). "Indios encomendados, indios registrados, indios omitidos por el visitador Luján de Vargas. Gobernación del Tucumán, siglo XVII”. Actas de las XI Jornadas Interescuelas/Departamentos de Historia: 1-25. San Miguel de Tucumán, Departamento de Historia. Facultad de Filosofía y Letras. Universidad de Tucumán. Disponible en Internet: http://cdsa.aacademica.org/ooo-108/1. Consultado el: 19 de julio de 2017

" Cornejo, A. (1945). Historia de la Propiedad Inmobiliaria de Salta en la época Virreinal, Buenos Aires, Ferrari hermanos.

»Doucet, G. (1986). Los réditos de Quilpo: funcionamiento de una encomienda cordobesa a fines del siglo XVI, Jahrbuch für Geschichte Lateinamerikas 23: 63-119.

" Gil Montero, R. (2012). San Antonio del Nuevo Mundo y las ciudades efímeras creadas por la minería de plata en los Andes coloniales. Ciencia Hoy 22 (127): 21-28.

" Giudicelli, Ch. (2007). Encasillar la frontera. Clasificaciones coloniales y disciplinamiento del espacio en el área diaguito-calchaquí (S. XVI-XVII). Anuario IEHS 22: 161-201.

» Giudicelli, Ch. (2011). "La raya de los pulares: a Raya de los pulares. Institution d'une frontière indienne coloniale au seindu Valle Calchaquí (1582-1630)" en Obregón Iturra, J. P.; Capdevilla, L. y N. Richard (eds.), Les indiens des frontieres coloniales; Amérique australe, XVle siecle/temps présent: 27-57. Rennes, Presses Universitaires de Rennes.

» Giudicelli, Ch. (2018). Disciplinar el espacio, territorializar la obediencia. Las políticas de reducción y desnaturalización de los diaguita-calchaquíes (siglo XVII). Chungara. Revista 
de Antropología Chilena 50 (1): 133-144.

» Gluzman, G. (2007). Minería y metalúrgica en la antigua gobernación del Tucumán (siglos XVI y XVII). Memoria Americana. Cuadernos de Etnohistoria 15 (1y 2): 157-184.

» González Rodríguez, A. (1982). Notas sobre el traslado de indígenas en la jurisdicción de Salta. Temas americanistas 1: 49-62.

» Levillier, R. (1920a). Gobernación del Tucumán: papeles de gobernadores en el siglo XVI. Documentos del archivo de Indias T. 1. Madrid, Imprenta de Juan Pueyo.

» Levillier, R. (1920b). Gobernación del Tucumán: papeles de gobernadores en el siglo XVI. Documentos del archivo de Indias T. 2. Madrid, Imprenta de Juan Pueyo.

»Lorandi, A. M. (1988). La resistencia y rebeliones de los diaguito-calchaquí en los siglos XVI y XVII. Revista de Antropología III (6): 3-17.

» Lorandi, A. M. (2005). The Spanish King of the Incas. The Epic Life of Pedro Bohorques. Pittsburgh, University of Pittsburgh Press.

» Lorandi, A. M. y R. Boixadós (1987-1988). Etnohistoria de los valles calchaquíes en los siglos XVI y XVII. Runa XVII-XVIII: 263-419.

» Mata, S. (2005). Tierray poder en Salta: el noroeste argentino en vísperas de la independencia. Salta, CEPIHA.

» Mignone, P. (2014). Fuentes para la localización y el estudio de las minas históricas del Nevado de Acay, departamento La Poma, Salta, Argentina. Memoria Americana. Cuadernos de Etnohistoria 22 (1): 65-92.

»Palomeque, S. (2006). La Historia de los señores étnicos de Casabindo y Cochinoca (1540-1662). Andes 17: 139-194.

»Pérez Sáez, V. y F. Ossán de Pérez Sáez (1997). El español de la Argentina (documentos para su historia). Volumen I. Salta, Gófica.

» Rodríguez, L. (2015). Explotaciones mineras intermitentes y promesas permanentes de riqueza. Descubrimientos, redescubrimientos y ordenamientos al sur del Valle Calchaquí, fines del siglo XVII-mediados del XIX. Población \& Sociedad 22 (1): 61-91.

» Sica, G. (2014). Las otras mitas. Aproximaciones al estudio de la mita de plaza en la jurisdicción de Jujuy, gobernación de Tucumán, siglo XVII. Anuario de Estudios Americanos 71 (1): 201-226.

» Tandeter, E. (1992). Coacción y Mercado. La minería de la plata en el Potosí colonial 16921826. Buenos Aires, Editorial Sudamericana.

» Tolosa, S. (2014). Una historia en primera persona sobre el territorio de Los Antes: la carta e Moisés Lozano a Francisco P. Moreno. Revista de Fuentes y Archivos 5: 152-165.

» Torreblanca, H. de ([1696]. 2007). Relación histórica de Calchaquí. Escrita por el misionero jesuita P. Hernando de Torreblanca y remitía al Padre Rector Lauro Núñez en 1696. Salta, Crivelli.

»Stern, S. (1992). Paradigmas de la conquista: Historia, Historiografía y Política. Boletín del Instituto de Historia Argentina y Americana “Dr. E. Ravignani” 6: 7-39. 